\title{
The Favourable Partner: An Analysis of Lianhe Zaobao's Representation of China in Southeast Asia
}

\author{
Daniel R. Hammond \\ University of Edinburgh
}

\begin{abstract}
Singapore has, since its founding, had a critical role regarding Southeast Asia's interaction with China. The city-state has acted as both an enthusiastic promoter of closer ties with China and also as one of the prominent supporters of a hedging strategy regarding the involvement of extra-regional powers in Southeast Asia. To date there has not been any substantial analysis of how China and Southeast Asia are represented in the local media. Given the ongoing significance of news media as a means to communicate ideas and agendas, to both online and offline audiences, this gap is notable. This article will contribute some initial findings based on an analysis of articles related to China and Southeast Asia in the Lianhe zaobao newspaper. Sino-Singaporean relations are presented in a positive sense regardless of whether the focus is economic, political, or social; in contrast, when discussing China and Southeast Asia as a region, issues of insecurity and other negative aspects become more prominent. This suggests that, while the Singaporean media reports China in a positive light regarding bilateral relations, there is a clear willingness to raise awareness of the broader regional challenges of China's rise. It plays the dual role of both friend and critic.
\end{abstract}

Keywords: Lianhe zaobao, Singapore, China, Southeast Asia, media, representation.

The relationship between the People's Republic of China ("PRC" or "China" hereafter) and Singapore has been a significant feature of the regional and international politics of Southeast Asia throughout the Cold War and post-Cold War eras. How these two states view each other and their respective roles in the region has been, and will be, key to the stable and prosperous development of the region. The relationship between the two states is multifaceted and complex. China has viewed Singapore as a source of investment and developmental knowledge which has manifested in numerous government-to-government and economic initiatives (Bolt, 1996; Lee, 2001; Lim \& Horesh, 2016; Pereira, 2002). Singapore has viewed China as a partner to engage with and a rising power which it has had to manage in the context of its regional priorities (Percival, 2007; Lee, 2001). Both countries are also critical to the region of Southeast Asia (Storey, 2013). Beyond the platitudes of elite engagement by government, how is this complex relationship represented? What messages do parts of the Singaporean media, for example, project regarding China and its rising influence in Southeast Asia?

It is widely accepted that the media can play a significant role in the construction of discourses (Fairclough, 2013), which can help to consolidate elite interests, be they associated with ostensibly democratic or authoritarian systems (Hermann \& Chomsky, 1995; Shirk, 2011). These studies and the subsequent discussions they have generated tend to focus on the domestic role of media in managing and defining the message received by their audience (see for example Herring \&

This research benefited from the support provided by the Universitas Indonesia through a 2015 Sinergisme Grant. 
Robinson, 2003; Mullen \& Klaehn, 2010; Thompson, 2009; and Yumul \& Özkirimli, 2000). The media, broadly defined, can and does reflect the ideas of the state when it comes to foreign policy. This is important as the media can present certain events and policies in an uncritical manner (Dickson, 1994) and be manipulated by public relations campaigns to build favourability towards certain countries (Manheim \& Albritton, 1984; Signitzer \& Coombs, 1992; Zhang \& Cameron, 2002). The development of a more nuanced understanding of media reporting, public diplomacy, and foreign relations has found new purchase in the articulation and discussion of soft power and how states can build favourability to better serve their foreign policy goals (Nye, 2005, 2008, 2011; Roselle, Miskimmon, \& O'Loughlin, 2014). With regards to Singapore, analysis of the role of the media has tended toward the domestic management of consensus (see discussion in Koh, 2006).

This article provides initial findings from a project on regional leadership in Southeast Asia regarding Singapore and China. It does not seek to explain why Singapore's relations are presented in a particular way or the extent to which this influences those who read the stories-this requires a different methodology and level of analysis; rather, the article interprets the content of news articles based on keyword analysis and interpretation of randomised extracts. This provides readers with an initial understanding of how particular parts of the news media in Singapore represent China's relationship with the city state and with Southeast Asia. To this end, the following article analyses the output of Lianhe zaobao $\square$ 合早 $\square$, or United Morning Post, with regard to Singaporean relations with China, and also China's relations with Southeast Asia as a whole, using a computer-assisted corpus analysis software programme, AntConc (Anthony, 2014). The stories were collected on the basis of searches for particular terms, and subsequently subjected to descriptive statistical and content analysis. The advantages of this approach are twofold. First, it allows for a large collection of stories to be analysed in a relatively short amount of time. Second, it is more objective in identifying particular trends from which interpretation can be based. While the final assessment of the significance of particular words or phrases is still subject to the individual researcher, the process of identifying these terms is done through a replicable process managed by the software. A degree of researcher bias is, therefore, removed from the process.

There were no particular expectations in terms of what results might be anticipated from the analysis. It is common to find China's bilateral relations with other countries to be framed as hot economics/cool politics, or as actively depoliticised (Hammond \& Jing, 2016). It could, therefore, be anticipated that relations between China and Singapore reflect this and that the economic aspect of relations is emphasised. In addition, while relations between China and Singapore have cautious periods, there are none of the tensions inherent to relations between China and other countries either in Southeast Asia or beyond-Singapore is not a claimant state in the South China Sea dispute, does not have ideological conflicts due to certain shared values, and there is also a shared cultural heritage between a majority of Singapore's population and the PRC. It is, therefore, anticipated that Singaporean representations of the relationship will tend towards more positive 
language and representation, especially regarding opportunities for cooperation and development.

Singapore also acts as a linchpin in the Southeast Asian region and the regional organisation of the Association of Southeast Asian Nations (ASEAN). Tensions between ASEAN and China have waxed and waned over the years, but the current period is one of increasing tensions which has undone, to a large extent, the significant gains made by China during its charm offensive of 1998- 2008 (Storey, 2013). Singapore, as the recent controversy over exports to Taiwan has demonstrated, is not immune from Chinese criticism (Chan, 2016). It could also, therefore, be anticipated that discussion of China and Southeast Asia highlights these tensions and the dangers of a destabilising region for both Singapore and the region more widely.

This is broadly speaking what the results found; when addressing SinoSingaporean relations the news articles tend to focus on the positive ties between the two states, and while economic relations get the most attention, there is also discussion of political and social ties. In contrast, discussion of Sino-Southeast Asian relations highlights more explicitly the dangers of increasing tensions. To this end, the article will be structured as follows. First, the significance of Singapore to the Southeast Asian region and to China will be explored further. This sets the foundation for the discussion which follows and explains why the question of what is discussed in the Singaporean media matters. This is then followed by a methodological discussion which outlines why Lianhe zaobao was selected, how articles were selected, descriptive statistics relating to the number of articles selected, preparation of the texts, the use of AntConc to analyse the texts, and a brief critical discussion of the strengths and weaknesses of such an approach. Having set out the methodological approach, the article will discuss initial findings based on the descriptive statistics generated. This consists mainly of two lists, the wordlist detailing the frequency with which a word is used, and the keyword list that details words which appear more or less often than expected compared to a selected corpus of words. Fourth, the article will discuss a first case based on the selection of a particular term, in this case the "South China Sea" (Nan Zhongguo Hai 南中国海), outlining how the articles which used the term portray differences in relations between Singapore and China and Southeast Asia respectively. Next, a second case will discuss the use of the term "develop" (fazhan $\square$ 展), which further highlights the differences in how Singapore relates to China and Southeast Asia. Finally, the article concludes by summing up the overall findings and argument, before highlighting the relative strengths and weaknesses of this approach, as well as future possible research.

The Linchpin: Why Singapore Matters to Southeast Asia and to China

Singapore is a geo-strategic and political linchpin in Southeast Asia, which means it is fundamentally important to both the region, and especially ASEAN as a regional organisation, and China. Furthermore, for cultural, economic, and political reasons Singapore is especially important to China. This does not mean, however, that the relationship between the two does not have some difficulties-in particular China 
struggles when managing expectations that close cultural ties should lead to political and economic benefits which run counter to Singapore's regional interests.

Singapore is important in Southeast Asia and for China for a multitude of reasons, a number of which will be detailed here. First, geo-strategically Singapore occupies a significant point in terms of maritime trade in the region as it sits on the crucial Straits of Malacca and Singapore, which serves a conduit linking East and Southeast Asia to the Indian Ocean, the Middle-East and beyond. This sea lane is crucial to many extra-regional powers, including China, as the security and free navigation of the Straits has implications for food and energy security, as well as more general trade (Febrica, 2017). Strategically, Singapore has also been a key actor in pushing particular agendas which have helped shape regional security and engagement with extra-regional powers in the years after its founding. For example, Singapore has taken the view that the region being dominated by any single superpower is to be avoided and this has led to the policy of hedging being adopted both by the citystate but also by the region through ASEAN. Singapore has also, through ASEAN, been a crucial contributor to the direction regional co-operation has taken and how ASEAN engages with other states (see for example discussion of hedging and Singapore's role in Chung, 2004; Kuik, 2008; Kuik et al., 2012; Medeiros, 2005).

Singapore is also important because, in a developing region which has experienced civil, sectarian and inter-state conflict, it is a success. Having survived the difficult circumstances of its founding as an independent city-state and the konfrontasi of Sukarno's Indonesia, Singapore has managed to emerge as a key actor in the region. Furthermore, Singapore has managed an ethnically diverse population, which is predominantly Chinese, to form a stable and coherent society. Arguably the alternative, demonstrated by its neighbours throughout the Cold War, of civil conflict driven by ethnic and sectarian hatred, damagingly unbalanced economic development policies, and embracing the political extremes of right or left would not have been to the benefit of either the people of Singapore or the region more widely. In this regard, Singapore has been a linchpin, of stability and success, in an unstable region.

In terms of its relationship with China, from the 1970s Singapore has walked a careful line in how it has viewed both its role in Southeast Asia and the emergence of China as a potential regional power. Singapore has exhibited certain leadership qualities in relation to the rise of China which are inextricably linked to its recognition that its ethnic identity is a source of potential hostility and division. While Singapore enthusiastically embraced the PRC in economic terms from the 1970s onwards, in political terms it has walked a careful line which saw it only recognise the PRC diplomatically once all other ASEAN members had done so in the early 1990s (Percival, 2007; Storey, 2013). In the last two decades Singapore has continued to engage China enthusiastically while also being aware of the challenges China's rise presents to Southeast Asia. Singapore's position regarding China has, therefore, two aspects. First, there is a cautiously enthusiastic engagement with China in terms of economic opportunities including significant investment in the PRC. Second, Singapore has sought to support China politically and bring it into the 
region but not at a cost of either its regional position-it will not be seen as China's proxy-nor at the cost of region itself. The stability of Southeast Asia and its regional organisation ASEAN has come first; and if this means bringing in other powers to balance the interests of another then Singapore will support this. Singapore therefore has supported China's engagement with Southeast Asia, but it has not been an unquestioning cheerleader, and has at the same time continued to cultivate relations with the United States (US), Japan, India, and other potential extra-regional powers which might balance China's influence.

The PRC's relationship with Singapore is also more nuanced than might first be anticipated. It has actively courted Singapore as an economic and political partnerbut there are also difficulties regarding the relationship which China appears to struggle with. Politically, China has viewed Singapore as a natural ally when facing criticism for its authoritarian political system as well as its human rights record. As the offspring of an alternative political tradition to that of the West, at least in their self-perceptions, both Singapore and China emphasise the more communitarian basis of their political systems and reject criticisms based on the Western tradition of human rights and liberal democracy (Roy, 1994). At times when China or Singapore are facing criticisms from Europe or the US they have been able to count on the support of each other.

For the PRC, Singapore also offers a vision of the future where economic dynamism and engagement with the global economy are married to a soft authoritarian de facto one party political system. The hope that the Singaporean model can offer China a guide to the future has driven some co-operation such as projects in Suzhou and Tianjin, although there have been problems with this cooperation because the cultural and political ties are not as close as had been assumed (Bolt, 1996; Lee, 2001; Lim \& Horesh, 2016; Pereira, 2002). Regardless of the difficulties, the idea that Singapore, through its management of the state, society, and the economy, offers China a model has been a consistent theme.

China also needs friends in Southeast Asia due to a difficult history in the region. Resentment and suspicion dominate the politics of some states which harbour memories of dynastic China's imperial ambitions or more recent difficulties associated with China's support of insurgent movements and ethnic Chinese unrest during the Cold War (Taylor, 1976). This is particularly crucial at a time when China's rise is viewed as both a threat and an opportunity not just in Southeast Asia but also globally. During periods of perceived good or bad neighbour policies in the region, Singapore is a potential ally based on the cultural, political, and economic ties between the two states. Although, as noted above, this is something which Singapore itself is aware of and will distance itself from when it undermines the citystate's other interests.

The nuanced nature of the relationship, and Singapore's tendency to look out for its own interests, means that there is some frustration in the relationship. Arguably, this is also born of China's recognition that Singapore, a relatively young city-state of only 5.6 million people, has an influence in Southeast Asia and independence of 
policy which appears to exceed its size. This periodically leads to outbursts by the PRC suggesting frustrations at the relationship where the relative size and weakness of Singapore is emphasised, such as the recent conflict over Singaporean exports to Taiwan (see for example Chan, 2016).

Both states have a significant role in Southeast Asia, although for different reasons. Singapore has been at the forefront of increasing regional interactions and a strong voice cautioning against any one state dominating the region be it the US, China or Indonesia. China has, as a consequence of its economic growth and increasing international assertiveness, been drawn further and further into Southeast Asia as both a welcomed partner for economic development and a suspected future hegemon asserting unreasonable territorial claims. How Singapore views the different states contending for the role of regional leader, or at least regional influencer, is significant because of the many important aspects of the citystate's geographic, economic and political position. How China is represented in Singapore's media is an important aspect of these developments, and how to analyse this is the topic of the next section.

\section{Methodology}

The newspaper selected was Lianhe zaobao. It is a daily broadsheet published by Singapore Press Holdings (SPH), with a daily circulation in 2014 of 187,900 (39,300 of which is digital) (SPH, 2015: 65). It is the largest Chinese-language newspaper in circulation in Singapore, although it is dwarfed by its English-language sister, The Straits Times. Because of its significant circulation and also its links with the established publishing stable of Singaporean news media, Lianhe zaobao is a good choice for analysing how China and the region is discussed. Additionally, the selection of the Lianhe zaobao provides the opportunity to analyse a newspaper which is not frequently the focus of academic attention in spite of its readership, and explores how an important issue is being presented in a forum which might be ignored or overlooked due to perceived insignificance or issues related to accessibility.

Stories were collected from the online version of the paper only. This was for practical reasons as the digital version is readily accessible and did not require a field visit to Singapore to access. The online version of the paper is limited in how far back stories go, and therefore the period from which stories were collected begins in September 2008, and ends in October 2015, when funding for the project which supported this research finished. Stories were collected via a search of the digital version of the paper using its own search engine. For the purposes of the larger project, which focused on ideas of regional leadership in Southeast Asia, the search terms were used to build up five collections of stories focused on China and its relations with Southeast Asia, and Singapore. In addition, one year of stories from a special heading, flagged by the newspaper itself, of stories on Sino-US relations were collected to offer a (limited) point of comparison. It is recognised that there are limitations associated with how the newspaper articles were collected. These include the search tool used; this will have some impact on the stories returned and the 
results of the analysis. For example, it is to be anticipated that for particular collections of stories, the corresponding search term used to collect the stories will appear disproportionately high. However, as a means to narrow down what might be hundreds or thousands of articles to something more manageable, this approach was deemed acceptable. It also ensures that materials collected are relevant to the focus of the investigation.

Once the stories were identified, they were copied from the web into individual text files (.txt) and saved with UTF-8 encoding to ensure they could be analysed using AntConc. Each story was saved using its headline and the date published. Where stories had not been saved as UTF-8, the programme UTF Cast Express was used to convert them (RotatingScrew, 2014). Once encoded correctly, the stories were then segmented so that AntConc would be able to recognise the Chinese characters as words rather than blocks of text. This was done using SegmentAnt, a tool designed for the segmentation of Chinese and Japanese scripts (Anthony, 2016).

With the texts prepared they were then analysed using AntConc. Initially, the collections of stories would be loaded and a wordlist generated. This lists all the words which appear in the texts by frequency, and forms the foundation of further analysis. It was my intention to look for words that appeared an unusually high number of times rather than just in high volume. In order to do this, a corpus list is required against which the stories can be compared. Section A (newspaper reportage) from the Lancaster Corpus of Mandarin Chinese (LCMC) was used as the corpus for comparison (McEnery \& Xiao, 2004). This was loaded and subsequently a keyword list was generated. This ranks words by their "keyness" or how unusually high or low they appear in the selected documents-this is determined as loglikelihood noting the difference between the two collections of documents. This process identifies terms which appear higher or lower than might be expected when the documents analysed are compared with the corpus.

The next step is to analyse what these words mean in isolation and also in relation with other words in the text. AntConc provides a range of tools for interpreting the use of language. In the case of this study, only the most basic Keyword in Context (KWIC) analysis was used. This essentially provides a quick method to click through from frequency and keyword lists to see the words in the context used. The researcher can set various parameters, such as the amount of surrounding text shown. There are more powerful tools available, such as using KWIC to focus on collections of words surrounding the keyword. This was used in the analysis but did not produce any usable results. This is likely because the sample size for each keyword was quite low relative to the type of corpus linguistic analysis the programme is designed to facilitate. AntConc allowed quick compilation of every instance of a particular keyword being used and for these examples to be extracted to a text file for further qualitative analysis. For this study, the keywords were extracted as part of 100-character chunks and subject to interpretation. A randomised sample of the extracts was analysed (20 from each collection). This was done for two reasons. First, randomisation ensures that samples analysed are not subject to selective bias. Second, the choice of 20 samples for each collection makes 
the data more manageable, allows for more words to be analysed, and ensures that a comparison between collections is conducted.

An advantage of using software like AntConc to support the analysis is that it allows for the prompt analysis of a large volume of material. This is, however, both a blessing and a curse because it means that a researcher could very quickly be swamped and subsequently get lost in data. This has led to a number of decisions being made regarding both the total volume of data analysed and how this data was analysed, which will be briefly set out and explained below. First, for the purpose of this article, the analysis has focused on only two of the collections, those for "China and Southeast Asia" and "China and Singapore". This was done in order to make the volume of materials more manageable and also to avoid going over materials which appeared in multiple collections. The search terms were chosen because they were closest to each other in terms of word order, both being "China and..." as well as producing a relatively similar number of hits. Second, the wordlists and the keyword lists generated were set at 50 and only the cases of words appearing more often than might be expected were investigated. However, underrepresented words offer an opportunity for future research.

Once lists are generated, it then becomes incumbent on the researcher to make decisions regarding which terms are to be investigated. This could be done based entirely on the rank of keywords and the frequency in wordlists, and the initial analysis set out below will address this. For those more inclined to linguistic analysis, rather than politics, the frequency of modal particles and common terms might be of more interest, but in this case, I investigated those examples where there were clear contrasts in frequency and keyness of words.

As noted briefly above, there are a number of issues which might be raised about such an approach, which should be dealt with before moving on to findings. First, while the use of computer assisted analysis does streamline a great deal of the process of collecting materials and analysing them, it does not completely remove the person from the research and therefore subjectivity is not removed entirely. Arguably it would, in the case of the subject for this article, not be desirable to remove choice as this might limit possible findings and there is also, of course, a significant interpretative element which remains even after generating the various lists which starts with the selection of which terms to investigate. Second, the material collected was in the first place determined by the results generated by a newspaper search function. This means that almost inevitably stories might not have been picked up, due to the terms used for example. However, this is not in and of itself a reason to reject such an approach-rather the findings just need to be set in their methodological context. Third, the use of such software for analysis, which moves beyond simply the words used to the context they are used in, means that reading and interpreting of the text is still a crucial part of the process. Therefore, while software like AntConc means that handling hundreds if not thousands of texts becomes possible, it does not remove the requirement that the findings get read and interpreted. As with the previous points, the researcher's role in the process is crucial and should not be forgotten. 


\section{Broad Trends}

As noted above, two collections of the five gathered were used for the purposes of this article, "China and Southeast Asia" and "China and Singapore". The section which follows will discuss the descriptive statistics generated and initial findings based on the relative ranking of certain words in the frequency word list and keyword list. For the "China and Southeast Asia" collection there were 98 articles which included the term, consisting of 13,299 word types (unique words) and 96,963 word tokens (individual words). For the "China and Singapore" collection there were 185 articles, 18,730 word types, and 165,408 word tokens. As noted in the previous section, both collections were compared against the LCMC A corpus.

In the case of these collections, the following was notable. In both collections, the specific terms for the search which led to selection (China in both, and Southeast Asia and Singapore for their relevant collection) all appeared in the frequency and keyword lists for the relevant collection. This is not a surprise or unforeseen outcome because, as noted earlier, the process for collecting materials would have built in a tendency for the frequent appearance of these terms. What is notable is that Singapore does not appear that frequently (relative to other terms) in the "China and Southeast Asia" collection; and, in the "China and Singapore" collection the term "Southeast Asia" did not make the top 50 frequency or keyword lists at all.

There are five observations that can be made based on the keyword and frequency lists. First, in the "China and Southeast Asia" collection, other extraregional actors are prominent-Japan and the US both appear in the top 50 for the frequency and keyword lists. However, in the "China and Singapore" collection, the terms do not feature in the top 50 list at all. This suggests that "China and Singapore" stories focus on bilateral relations between the two states, whereas the "China and Southeast Asia" stories take a more regional view that involves other actors. Second, the term for state or country (guo 国) appears in both collections, but is higher in the "China and Southeast Asia" stories. This makes sense if it is assumed that the stories covering the region will be discussing the key regional actors who are mostly states. Third, terms which might suggest negative or problematic aspects of the relationship between China and the region only appear in the top 50 list for "China and Southeast Asia" stories and not for "China and Singapore". This includes reference to specific issues which are currently, and during the period the stories collected covered, negative, such as the South China Sea (Nan Zhongguo Hai 南中国海), in addition to terms which are open to more interpretation but imply a negative or problematic situation such as "issue" or "problem" (wenti $\square \square$ ) and “security" (anquan 安全). Fourth, terms which suggest a more positive relationship with China, or more positive outcomes, do appear in both collections but are more frequently used, and more key, in the "China and Singapore" collection. This includes terms such as "cooperation" (hezuo 合作) and "develop" (fazhan $\square$ 展), which tend to be positively deployed when discussing state-to-state relations. Fifth, the term "economy" (jingji $\square \square$ ) is used more frequently and is more key in the "China and Singapore" stories. This loosely 
supports the assumption that bilateral relations with China tend to be depoliticised and/or reduced to economic exchanges.

Overall, a review of the frequency and the keyword lists suggests the following. First, when discussing China and Southeast Asia, the newspaper articles are more inclined to discuss things in broader terms and include extra-regional actors such as the US. This suggests a broader view, which looks beyond bilateral relations, being taken in these stories. Second, problematic aspects of China's relations with Southeast Asia are more likely to be discussed in articles which focus on the region rather than bilateral relations with China. This suggests that discussing the region gives a forum in which to highlight the more problematic aspects of China's engagement, including specific issues like the South China Sea, as well as terms which denote problematic relations such as the term wenti and "security" /"safety". Third, and in contrast, more positive aspects of China's engagement are highlighted in the discussion of China and Singapore. The expectation that the economy would get a high priority, outlined in the early parts of this article, is supported by the high frequency and keyness of the term relative to the other collection. In addition, positive terms like "cooperation" and "development" are also discussed with an unusual frequency in stories related to China and Singapore. Overall, this suggests that when discussing China and Singapore specifically, the articles tend toward more positive interpretations of China's role. In contrast, discussion of China and Southeast Asia provides an opportunity, and arguably a need due to the circumstances, to highlight the problematic aspects of China's role in the region. These suggestions are only based on an examination of the lists generated from the stories collected and, therefore, to confirm or counter these findings it is necessary to focus on the texts and the context in which certain keywords are used.

\section{The Varied Use of the South China Sea}

Due to the heightened tensions in the South China Sea and its significance as an issue to the direction that Sino-Southeast Asian relations take, as well as the impact on particular bilateral relationships, the term was selected for further examination. It was also chosen because it offered a significant contrast between the two collections; for the "China and Southeast Asia" collection the term scored highly for keyness, coming $22^{\text {nd }}$ in the keyword list, but falling outside the frequency list (166 instances). This indicates that the term appeared an unusually high number of times relative to its frequency and compared with the LCMC A corpus. In the "China and Singapore" collection, the term appeared a small number of times, 28 in total, and did not score highly on either the frequency or the keyword lists. Because of the political tensions inherent in discussion of the South China Sea, the term is also worth investigating because it is likely that if there are any differences in how a term is being framed, then it will be regarding a term which is loaded with political significance for the parties involved. It is expected that tensions and concerns would be highlighted when discussing the region as a whole, whereas discussion of the bilateral relationship would not include such concerns, or at the very least they would be framed as less problematic. The findings for this section do broadly follow 
these expectations, but not quite as anticipated. A significant factor in determining how the term is being framed is who is being reported, and as will be shown, different actors and voices are given space to articulate their points of view in the two collections - this then explains the differences in how the term is framed in the stories collected.

The randomised extracts for the "China and Southeast Asia" stories show that the situation is viewed as problematic due to the complex nature of issues in the South China Sea and the long-term impact tensions might have. This is in part because of the fluid nature of the problem as it is ever-changing and unpredictable (Lianhe zaobao, 2011b). The main negative is not the problem in and of itself, but the impact tensions over the South China Sea have on possible co-operation in other areas (Cai, 2014). The complexity of the problem is noted in one extract which warns that the South China Sea should not be viewed through the prism of a single national or nationalist perspective (Zhao, 2010). Historical tensions in the region, due to global security issues, are also noted. Both SEATO and the Cold War were noted as a check on China in the South China Sea-a sword hanging over China-at the time (Ma, 2012).

The role of the US tends to be presented through the prism of whoever is being reported. So it is neutrally reported in some instances (Cai, 2014). In other extracts, Clinton is reported as against escalation and against China taking action (Cai, 2012). When Chinese representatives or media are reported commenting on the US, it is presented negatively (Lianhe zaobao, 2014; Cai, 2012). Chinese domestic opinion is also noted as being unfavourable to the US due to its position on both the Diaoyu and South China Sea disputes, although both China and the US are reported as making positive comments through their representatives regarding the possibility of working together (Cai, 2012).

The discussion of China is mixed in this collection of texts. China is presented as not having the capability to resolve the problems in South China Sea bilaterally (Zheng, 2010), although Chinese representatives are reported as presenting the contrary (Lianhe zaobao, 2014). China is also presented as a military threat due to the capability of the Dongfang 21-D missile providing capability to cover the South China Sea (Chosun-Ilbo, 2010). This sets up an interesting contrast in how the stories present China. On the one hand, China is presented as unable to resolve issues in the region, and on the other, it is a threat.

China and ASEAN's relationship is presented as problematic due to the South China Sea, but full of possibility. Economic ties are noted as trumping territorial disputes for ASEAN, but this is problematized by the possibility that the reverse is true for China (Ma, 2012). The "Code of Conduct of Parties in the South China Sea" (CoC) is highlighted as the next step in the relationship (Cai, 2012). It is noted that ASEAN has accommodated China, Korea, Japan, and the US already, and that the "Declaration on Conduct of Parties in the South China Sea" (DoC) is seen as the cornerstone of an ASEAN-China security order and a foundation for mutual trust for the future (Zheng, 2011). The base established by both the DoC and a future CoC, 
along with economic cooperation, is the foundation for good relations (You, 2013). Energy security is one area where cooperation between China and Southeast Asia on the South China Sea is seen as "important" (zhongyao 重要) (Zhao, 2010). These statements suggest an optimistic or positive interpretation of the future of China and its relationship with Southeast Asia, despite the myriad challenges presented by the South China Sea.

The analysis of the "China and Singapore" stories is similar to the "China and Southeast Asia" collection in that there is no dominant pattern. It is, however, drawn from a much smaller sample of stories. China does have a clearer voice in relation to the South China Sea due to the reporting of particular actors' views on the matter. Notably, Foreign Minister Wang Yi is reported and this reflects on the position being articulated. For example, in one sample, he is reported saying that the South China Sea is the front line in China's defence of its sovereignty (Zhao, 2015). The South China Sea is also noted as a domestic concern for China, not just an international problem, which is a position not often found in the media when discussing, what appears on the surface, an international issue (Zhao, 2015). The actions of other states are noted, in particular the naval presence of the US, the pursuit of arbitration by the Philippines, and Vietnam's claims (Zhao, 2015). In these extracts, China is presented as one actor among many in the South China Sea and no judgment or responsibility for developments is attributed to any one of them.

This does not mean that China and other states in the South China Sea are immune from criticism. China's actions are highlighted as responsible for rising tensions in the region, as well as for provoking actions by other states (Zhao, 2015). The US, discussed as a historical actor constraining and facilitating actions, is described as a problematic actor in the region-the impression is given that the Philippines would not act without US support and the US would not be able to act in the region without the support of other states (Lianhe zaobao, 2009a). Finally, it is repeatedly noted that tensions related to the South China Sea are having a negative impact on other aspects of China's relations with the region; in particular, uncertainties related to the Maritime Silk Road are rooted in a lack of certainty stemming from China's activities in the South China Sea. What stands out is that the tone of the stories, in terms of how favourable they appear to be, depends on the comments which are being reported. In the "China and Singapore" stories, the prevalence of the Foreign Minister of the PRC, Wang Yi, as the source of comments clearly links to extracts which are more favourable to China's position.

\section{The Different Forms of Development}

In an effort to seek a balanced analysis, the next term selected was chosen on the basis of a high ranking in the keyword list, and also because it might highlight more positive aspects of the relationship between China and both Singapore and/or Southeast Asia. The term fazhan $\square$ 展 is translated as "to develop", "develop", or "development" (which will be used interchangeably from now on) and frequently appears in texts when discussing, for example, economic development (jingji fazhan 
$\square \square \square$ 展). The term was chosen because of its relatively high frequency in both collections, where it was 16th in the "China and Singapore" texts and 38th in the "China and Southeast Asia" Asia texts. There was a big difference in the number of times the term was used. In the "China and Singapore" texts it appeared 664 times, whereas in the "China and Southeast Asia" texts it appeared 226 times. In terms of keyness, when compared against the corpus, fazhan ranked 9th in the "China and Singapore" texts and 37th in the "China and Southeast Asia" texts. The higher frequency and keyness of the term in the "China and Singapore" texts is already suggestive of a different approach between the two, with a greater emphasis on development, suggesting a more positive view of this particular relationship.

In the randomised extracts for "China and Southeast Asia" texts which included fazhan, the following points were discerned. Generally speaking, there was a diverse range of stories in this sampling, which covered everything from historical geopolitics in the region through to museum exhibits. A number of extracts focused on discussion of China as an emerging threat in the region, and how this might develop further. Extract 9 notes that the US and other states might seek to contain China, but this is something China can resist as it is not weak (Zheng, 2011). The lack of trust between China and Western nations is noted as a problem for the region (Lianhe zaobao, 2011a). This has developed since the great financial crisis, when China began to ascend in the region and could be perceived as a threat (Zheng, 2010, 2011). However, in another extract, China's rise is not viewed as inevitable but as a consequence of its economic development (Zheng, 2010). The outcome is, however, the same with China viewed as a potential threat in the region. The US is also a source of discussion. In some extracts the US is the container of China. This role is a consequence of ASEAN's lack of unity regarding how to deal with China and the various territorial disputes which have emerged (Zheng, 2010). Another extract cites the history of extra-regional involvement in Southeast Asia because of trade (Lianhe zaobao, 2010). Taken together these extracts suggest a multifaceted view of China, and to some extent Southeast Asia's limitations, which mean that China's rise is viewed negatively. It should be noted that a number of these stories are opinion pieces authored by an academic and, therefore, will offer a different view of China and Southeast Asia than if reporting an event or speech.

The discussion of ASEAN in the extracts is multifaceted, reflecting both positive and negative views. The positive discussions focus on the economic relationship between China and the organisation. Ties are complex with different political and economic ties between China and the members of ASEAN (Ma, 2012). The length of China's relationship with ASEAN and the number of agreements signed is also noted (Ma, 2012). However, not much else is offered in terms of discussion of China and ASEAN beyond this measuring of relations, and the suggestion that the relationship is complicated by the multi-member nature of ASEAN as an organisation.

There are two extracts which note the difficulties in the relationship. These highlight, in particular, the problem of sovereignty disputes in the region. What is notable about these extracts is that they are putting across China's view, in China's voice. Again, the more critical or controversial aspect of a story is being delivered by 
using the source of the story, rather than it being part of the newspaper and its reporters' voice. For example, in one extract, "China says" is used when explaining that there is no dispute with Vietnam over the Paracel Islands and that the US has no role in the region as it is not a claimant in the South China Sea (Lianhe zaobao, 2014). In another extract, it is noted by Chinese officials that cooperation with ASEAN is hoped for and that the issue of the South China Sea has derailed the agenda since 2010. Furthermore, the issue has been artificially hyped and enlarged (Cai, 2014). However, there is also one extract which is supportive of closer cooperation with the US although this is, again, a reflection of the words from officials (Cai, 2012).

Other extracts address a range of different issues relating to Southeast Asia. This includes the finding of porcelain at the Bukit Bintang tombstones in Malaysia (Lianhe zaobao, 2013), the regional challenge of food security due to climate change (Wu, 2013), and the opportunities and challenges of developing Yunnan Province in China as a link with South and Southeast Asia (Qin, 2010). Overall, the "China and Southeast Asia" samples constructed Southeast Asia as facing a difficult relationship with China. There was a lot of discussion of the threats posed by political tensions in the region, and the influence of extra-regional powers.

In the "China and Singapore" texts, a much stronger pattern emerges, with the extracts focusing on bilateral economic ties between the two states. The significance of Singapore to China and vice versa is repeated in a number of extracts, which outline the trade and investment ties through some core statistics-China is Singapore's 3rd largest trading partner, Singapore is China's 11th largest trading partner, Singapore was the largest source of FDI into China in 2013, China as the 5th largest Asian investor into Singapore in 2012-which paints a consistent message of close and important economic ties (Shen, 2014; You, 2010; Lianhe zaobao, 2010c). Extracts also note specific bilateral economic projects between China and Singapore, providing a level of detail regarding the relationship between the two which is lacking when it comes to discussion of Southeast Asia. These specific examples are Tianjin Ecocity in Northern China (Zhang, 2011; Shen, 2012) and The Interlace, a residential project in Singapore (Zhao, 2013). Finally, one extract also notes the extensive network of offices representing Singaporean interests in China developed by the Singapore Enterprise Development Board (Lianhe zaobao, 2010c).

There is also a clear emphasis on bilateral political ties between the two states. This takes the form of noting the development of ties between China and Singapore when they were ruled by Deng Xiaoping and Lee Kuan Yew respectively, a point also noted by Lim and Horesh (2016). These stories relate in part to the unveiling of a monument to Deng in Singapore but still they do highlight that the relationship between the two is not just economic or cultural (Zhang, 2011; Sun, 2009). The contemporary continuation of this relationship is noted in an extract discussing Prime Minister Lee Hsien Long and President Xi Jinping attending the unveiling of the Deng monument (Zhang, 2010). Two extracts citing Xi's predecessor, Hu Jintao, also highlight the political relationship between the two states. These extracts note China's developmental stage, China's admiration for Singapore, and the fact that a stable and prosperous China is good not just for China but for the region as a whole 
(Lianhe zaobao, 2009b; Han \& Li, 2009). Another extract notes the progress China has made developmentally and also appears to support the status quo in the PRC by arguing that there is sufficient feedback for citizens (Gu, 2015). There is also one extract which emphasises the personal ties between China and Singapore. In this instance the text focuses on Lin Song, who came to Singapore to study. Instead of returning to China, he married a Singaporean and settled down in the city (Miao, 2011).

In contrast to the "China and Southeast Asia" texts the "China and Singapore" collection presents a much more coherent set of messages in spite of the random sampling. It also presents a much more positive set of stories. This ranges from the deep and ongoing economic ties between the two states to the political and personal stories which tie them together. This is altogether lacking in the "development" extracts for the "China and Southeast Asia" stories which still discuss the threatening aspect of China's engagement with the region as well as the consequences of the involvement of extra-regional actors. This collection of stories, analysed through the term "development", does highlight a clear distinction between the two sets of texts. Those addressing China and Singapore are focused on the positive regardless of whether it is economic, political, or personal stories, whereas those discussing China and Southeast Asia are much more mixed, consisting of both the possibility of cooperation but also the threat of China destabilising the region, or of other powers becoming involved as a consequence of China's rise.

\section{A Critical Friend?}

The relationship between Singapore, its neighbours in Southeast Asia, and China will be critically important as we enter a period of uncertainty in what has not, historically, been a region known for its stability. How Singapore presents itself, and its priorities, to the region and to China will be a significant factor in how developments play out. Singapore is important to the region as a founding member of ASEAN, as its most developed state, for its geostrategic position, for the composition of its population, and because most of the time it is viewed favourably by China. A great deal is assumed about the relationship between Singapore and China but, with the notable exception of a relatively small selection of studies discussed earlier, there has not been much in the way of detailed analysis. This article has set out to contribute to understanding the dynamic between Singapore, China, and Southeast Asia by exploring how the relationship between the three is articulated through the Lianhe zaobao, a Singaporean Chinese-language daily newspaper.

The Lianhe zaobao newspaper was chosen because, of the Chinese-language newspapers in Singapore, it has the widest daily circulation but is infrequently referred to, and is therefore under-researched. It is also a member of the dominant Singapore Press Holdings, and so might be anticipated to be on message in terms of what the Singaporean government, journalists, and those interviewed wish to 
communicate. The computer programme AntConc was used to aid in the analysis of the materials using a number of functions available including frequency word lists, keyword lists, and keyword in context (KWIC). Although KWIC did not prove to be helpful due to the small sample size of the text, the other functions enabled the analysis of a large number of stories in a relatively short space of time. While this certainly smoothed the process of analysing the texts, at the same time, the relative ease of generating data was almost overwhelming. The programme is, however, overwhelmingly useful and opens up a great deal of possibilities for analysing Chinese-language texts in the future.

The analysis also presents some challenges which could be addressed in future research on the subject. From a methodological perspective, mixing interpretation of text extracts with corpus linguistic analysis means that some of the meaning of texts is lost unless consciously addressed at the beginning of the process. In this article the text was dealt with as a series of extracts, but this means that the author of the text, where and when the story appears, and the form the story takes (editorial, opinion piece, or more conventional story), are not factored into the analysis. Furthermore, the analysis as presented here is solely interpretative and any explanation as to why the themes identified emerged would require a broader analysis of the Singaporean media landscape and its relationship with the state.

A final point: the analysis presented above is a snapshot from a certain period of time. This is a problematic, if unavoidable, outcome of the analysis because relations between countries change. Such an analysis will not reflect these developments. The conclusion outlined below needs to be situated within the broader context of the ongoing development of Sino-Singaporean relations. These have, of late, become a bit more intense than in previous years. For example, in early 2017 nine Singaporean Terrex armoured vehicles were returned by Hong Kong, having been seized in November 2016 on their return from Taiwan (BBC, 2016, 2017). This event followed soon after a story in September 2016 involving China's Global Times (Huanqiu shibao $\square$ 球 $\square \square$ ) newspaper, which was critical of Singapore (Zhou, 2016). This culminated in Singapore's ambassador to China releasing an open letter admonishing the editor and the contents of the story (Loh, 2016). These difficulties in the relationship have carried on into 2017 with the Global Times publishing at least three additional stories which are highly critical of Singapore's government (Polin, 2017; Global Times, 2017; Yang, 2017). While it is often noted that the Global Times does not equate to the Chinese government, the diplomatic spat between China and Singapore has continued over 12 months. It is almost inevitable this will have had some negative impact on the relationship. These developments, and the potential impact they have had on the relationship, is one area that further research on how China is represented in Singaporean news reports could and should address.

Having said this, the findings broadly reflected what was anticipated in the initial stages of the article. The newspaper would use Southeast Asia as a proxy for criticism of China whereas stories which discussed China and Singapore would focus on the more positive aspects of the relationship. In the use of the terms "South China Sea" and "development", the stories addressing Southeast Asia were much 
more varied and included stories that were critical of China's role in the region, as well as highlighting the problem of the China threat, explaining and criticising the involvement of the US, and raising concerns about the behaviour of other states. In contrast, the stories regarding "China and Singapore" were overwhelmingly positive and focused on economic ties, political links, and personal stories which brought China and Singapore together. The contrast was stark in both terms analysed for the purposes of this article, in spite of them being very different and having very different profiles in terms of frequency and keyness in the texts. While recognising the limitations of the analysis conducted, this article does indeed show that, in this specific case, Singapore's press does act out the role of China's critical friend in Southeast Asia, and uses the region as a means to deliver its concerns and criticisms regarding China's actions. What will be of interest is how this role develops in the future, as China becomes more assertive in both the region and also towards Singapore.

\section{References}

Anthony, Laurence (2014), AntConc (Version 3.4.3), Tokyo: Waseda University, available at: http://www.laurenceanthony.net/ (accessed 06.02.2017).

- - (2016), SegmentAnt (Version 1.1.0), Tokyo: Waseda University, available at: http://www.laurenceanthony.net/software/segmentant/ (accessed 06.02. 2017).

$B B C$ (2016), "Hong Kong Armoured Vehicles Seizure: What We Know", November 25, available at: http://www.bbc.co.uk/news/world-asia-38101345 (accessed 05.09.2017).

- - (2017), "Terrex: Hong Kong to Return Singapore Army Vehicles", January 25, available at: http://www.bbc.co.uk/news/world-asia-38740651 (accessed: 05.09.2017).

Bolt, Paul J. (1996), "The New Economic Partnership between China and Singapore", Asian Affairs: An American Review 23(2): 83-89.

Cai, Yongwei (2012), "Xilali: Zhongmei wushi hezuo hen zhongyao" (Hillary: Sino-US cooperation is very important), Lianhe zaobao, September 5, available at: http://www.zaobao.com.sg/media/photo/story20120905-136665\#stha sh.VK PzJBYz.dpuf (accessed 08.10.2015).

- - (2014), "Zhong zhi mei xu Nan Zhongguo Hai shengsuo guo 'dongjie' tiaoxin bu xianshi" (China refers to USA calls for 'freeze' by South China Sea claimant states as unrealistic, provocative), Lianhe zaobao, May 8 , available at: http://www.zaobao.com.sg/special/report/politic/southchinasea/story 2014 0805-373745\#sthash.ZN7lbmyz.dpuf (accessed 08.10.2015).

Chan, Minnie (2016), "How Singapore's Military Vehicles Became Beijing's Diplomatic Weapon", South China Morning Post, December 3, available at: http://www.scmp.com/week-asia/politics/article/2051322/how-singapore smilitary-vehicles-became-beijings-diplomatic (accessed 06.2017).

Chosun-Ilbo (2010), "Mei: Zhongguo yanfa 'hangmu shaoshou' fan jian dandao daodan" (USA: China researching 'anti-aircraft carrier killer' anti-ship missiles), Lianhe zaobao, August 30, available at: 
http://www.zaobao.com.sg/wencui/politic/story20100830-194678\#sthas

h.rO0JnoT6.dpuf (accessed 06.10.15).

Chung, Chien-peng (2004), "Southeast Asia-China Relations: Dialectics of 'Hedging' and 'Counter-Hedging'", Southeast Asian Affairs, 35-53.

Dickson, Sandra H. (1994), "Understanding Media Bias: The Press and the U.S. Invasion of Panama", Journalism Quarterly 71(4): 809-819.

Fairclough, Norman (2013), Critical Discourse Analysis, 2nd ed., Abingdon: Routledge.

Febrica, Senia (2017), Maritime Security and Indonesia: Cooperation, Interests and Strategies, Abgindon: Routledge.

Global Times (2017), "Singapore's Flip-Flop Stance Toward China Hard to Change", June 11, available at:

http://www.globaltimes.cn/content/1051170.shtml (accessed 05.09.2017).

Gu, Gonglei (2015), "Gu Gonglei: he yiyuan gongjin zaocan" (Gu Gongli: breakfast with MPs), Lianhe zaobao, February 18, available at: http://www.zaobao.com.sg/forum/zaodian/hai-shang-hai/story20150218448290\#sthash.Rkv5xK6b.dpuf (accessed 08.10.15).

Hammond, Daniel R. and Jing (2016), "Weak Politics-Depoliticisation as Strategic Choice: An Analysis of Chinese Priorities in Sino-EU Relations", 73-90, in Jan van der Harst and Tjalling Halbertsma (eds.), China, East Asia and the European Union: Strong Economics, Weak Politics, Leiden: Brill.

Herman, Edward S. and Noam Chomsky (1995), Manufacturing Consent: The Political Economy of the Mass Media, London: Vintage.

Han, Yonghong and Li Yunlin (2009), "Hu Jintao di xin fangwen shi xuanbu Zhongguo jie chu da xiongmao get woguo" (Arriving for new visit Hu Jintao announced that China would give our country a giant panda), Lianhe zaobao, November 12, available at: http://www.zaobao.com.sg/special/report/po litic/apec2009/story20091112-99825\#sthash.zOhLZ36y.dpuf (accessed 16.10.15).

Herring, Eric and Piers Robinson (2003), "Too Polemical or Too Critical? Chomsky on the Study of the News Media and US Foreign Policy", Review of International Studies 29: 553-568.

Koh, Aaron (2006), "Working Against Globalisation: The Role of the Media and National Education in Singapore", Globalisation, Societies and Education, 4(3): 357-370.

Kuik, Cheng-Chwee (2008), "The Essence of Hedging: Malaysia and Singapore Respond to a Rising China", Contemporary Southeast Asia: A Journal of International and Strategic Affairs 30(2): 159-185.

Kuik, Cheng-Chwee, Nor Azizan Idris and Abd Rahim Md Nor (2012), "The China Factor in the U.S. 'Reengagement' with Southeast Asia: Drivers and Limits of Converged Hedging", Asian Politics and Policy, 4(3): 315-344.

Lee, Lai To (2001), "The Lion and the Dragon: A View on Singapore-China Relations", Journal of Contemporary China 10 (28): 415-425.

Lianhe zaobao (2009a), "Li Guangyao weihe tuichu 'Yi Mei zhi Hua' lun?" (Why did Lee Kuan Yew introduce the theory of 'using China to dominate the USA'?), November 5, available at: http://www.zaoba o.com.sg/forum/letter/us/story20091105-48944\#sthash.6tt6gUjH.dpu (accessed 08.10.15). 
-- (2009b), "Li zizheng tan zhongguo gaige kaifang lu" (Advisor to Lee discusses China's reform and opening), January 5, available at: http://www.zaobao.com.sg/special/face2face/story20090105-28617\#stha sh.b7fo4X3K.dpuf (accessed 08.10.15).

- - (2010), "500 nian dongxifang shiji chongxin pincheng yu Zhong Mei boyi" (The 500-year global rebalance of East and West and the Sino-USA game), January 12, available at: http://www.zaobao.com.sg/forum/letter/us/story 2010011250120\#sthash.ER6FtbNY.dpuf (accessed 08.10.15).

- - (2010c), "Xiezhu bendi qiye he Zhongguo qiye gongtong fazhan" (Helping local and Chinese enterprises to develop together), October 1, available at: http://www.zaobao.com.sg/special/sg-cn/business/story20101001-10795 7\#sthash.33DcHBSj.dpuf (accessed 06.10.15).

- - (2011a), "Jinri Zhongguo waijiao kunjude huigu he fanyi" (Review and reflection on China's current diplomatic dilemma), January 2, available at: http://www.zaobao.com.sg/forum/letter/us/story20110102-50379\#sthas h.4YJFXg4Q.dpuf (accessed 06.10.15).

- - (2011b), "Nanhai wupiande daijia" (The cost of misjudgement in the South China Sea), June 20, available at: http://www.zaoba o.com.sg/forum/letter/others/story20110620-40925\#sthash.L31mjsK4.dp uf (accessed 16.10.15).

- - (2013) "Lishi zoudao-Wuji Bulang ting mubei shuo gushi" (History takes the road-Bukit Bintang listens to the story of the tombstones), May 26, available at: http://www.zaobao.com.sg/lifestyle/travel/singapore/story2

0130526208724/page/0/1\#sthash.JHXL7I26.dpuf (accessed 06.10.15).

-- (2014),"Fu Ying: Zhongguo he Dongnanya xuyao shensi huxin wenti" (Fu Ying: China and Southeast Asia need to reflect on the issue of trust), May 30, available at: http://www.zaobao.com.sg/special/report/singapore/sld/ news/story20140530-349153\#sthash.9k9sRVv3.dpuf (accessed 08.10.15).

Lim, Kean Fan and Niv Horesh (2016), "The 'Singapore Fever' in China: Policy Mobility and Mutation", The China Quarterly, 228: 992-1017.

Loh, Stanley (2016), “Full Text of Ambassador Stanley Loh's Letter to Global Times Editor-in-Chief Hu Xijin, in Response to an Article by Global Times (Chinese) dated 21 September 2016", available at: https://ww w.mfa.gov.sg/content/mfa/overseasmission/beijing/consular_services/consular _updates/2016/201609/global_times.html (accessed 05.09.2017).

$\mathrm{Ma}$, Zhiwen (2012), "Zhongguo Dongmeng guanxi zhi 1-2-3" (The 1-2-3 of Sino-Asean Relations), Lianhe zaobao, June 19, available at: http://ww w.zaobao.com.sg/forum/letter/others/story20120619-35292\#sthash.k8h1 veBU.dpuf (accessed 06.10.15).

Manheim, Jarol B. and Robert B. Albritton (1984), "Changing National Images: International Public Relations and Media Agenda Setting", The American Political Science Review, 78(3): 641-657.

McEenery, Tony and Richard Xiao (2004), The Lancaster Corpus of Mandarin Chinese (LCMC), Lancaster: Lancaster University, available at: http://www.lancaster.ac.uk/fass/projects/corpus/LCMC/ (accessed 06.02.2017).

Medeiros, Evan S. (2005), "Strategic Hedging and the Future of Asia-Pacific Stability", The Washington Quarterly 29(1): 145-167. 
Miao, Fengtian (2011), "Laizi Zhongguo de lüshi wei liangdi qiye chongdang runhuaji" (Lawyers from China act as lubricant for businesses from both places), Lianhe zaobao, February 7, available at: http://www.zaobao.com.sg/social/crossroads/general/story20110207-53 785\#sthash.Sw6hDhGh.dpuf (accessed 07.10.15).

Mullen, Andrew and Jeffery Kalehn (2010), "The Herman-Chomsky Propaganda Model: A Critical Approach to Analysing Mass Media Behaviour", Sociology Compass 4(4): 215-229.

Nye, Joseph (2005), Soft Power: The Means to Success in World Politics, New York: PublicAffairs.

- - (2008), The Powers to Lead: Soft, Hard, and Smart, Oxford: Oxford University Press.

- - (2011), The Future of Power, New York: PublicAffairs.

Percival, Bronson (2007), The Dragon Looks South: China and Southeast Asia in the New Century, Westport: Praeger Security International.

Pereira, Alexius (2002), "The Transformation of Suzhou: The Case of the Collaboration between China and Singapore Governments and Transnational Corporations (1992-1999)", 121-134, in John R. Logan (ed.) The New Chinese City, Oxford: Blackwell.

Polin, Thomas Hon Wing (2017), "Singapore Risks Being Left out of the Loop on B\&R Regional Integration", Global Times, available at: http://www.globaltimes.cn/content/1048116.shtml (accessed: 05.09. 2017).

Qin, Guangrong (2010), "Yunnan 'Quanqiuhua' de Nanya jiyu" (The opportunity of Yunnan's "Globalisation" for South Asia), Lianhe zaobao, August 2, available at: http://www.zaobao.com.sg/wencui/politic/story20100802196372\#sthash.3sjkdl6K.dpuf (accessed 08.10.15).

Roselle, Laura, Alister Miskimmon and Ben O'Loughlin (2014), "Strategic Narrative: A New Means to Understand Soft Power", Media, War \& Conflict, 7(1): 70-84.

RotatingScrew (2014), UTFCast Express (Version 1.0.5.22), California, USA: RotatingScrew, available at: https://www.rotatingscrew.com/utfcast-expre ss.aspx (accessed 06.02.2017).

Roy, Denny (1994), "Singapore, China, and the 'Soft Authoritarian' Challenge", Asian Survey, 34(3): 231-242.

Shen, Zewei (2012), "Li Yixian: Zhong Xin Tianjin shengtaicheng miandui jinzheng xu xiyin renqi" (Li Yixian: Sino-Singaporean Tianjin eco-city faces competition to gain popularity), Lianhe zaobao, March 29, available at: http://www.zaobao.com.sg/special/sg-cn/business/story20120329-10726 1\#sthash.cMJBUsMS.dpuf (accessed 07.10.15).

- - (2014), "Li Zongli: '21 shiji Haishang Sichou zhi Lu' youli yu ben quyu fazhan" (Premier Li: "The 21st century Maritime Silk Road" is beneficial for the development of the region), Lianhe zaobao, September 11, available at: http://www.zaobao.com.sg/special/sg-cn/bilateral/story20140911-38778 1/page/0/1\#sthash.sbrBFxJB.dpuf (accessed 16.10.15).

Shirk, Susan L. (2011), "Changing Media, Changing China", 1-37, in Susan L. Shirk (ed.), Changing Media, Changing China, Oxford: Oxford University Press.

Signitzer, Benno H. and Timothy Coombs (1992), "Public Relations and Public Diplomacy: Conceptual Convergences", Public Relations Review, 18(2): 137-147. 
SPH (2015), Annual Report 2015: People with Passion, Singapore: Singapore Press Holdings, available at: http://www.sph.com.sg/system/misc/annualr eport/2015/SPH_AR2015_Final.pdf (accessed 06.02.2017).

Storey, Ian (2013), Southeast Asia and the Rise of China: The Search for Security, Abingdon: Routledge.

Sun, Jingfeng (2009), “Deng Xiaoping shuo jiejian Xinjiapo zhishi ke taohua?” (Deng Xiaoping said drawing lessons from Singapore only out of courtesy?), Lianhe zaobao, March 30, available at: http://www.zaobao.co m.sg/special/sgcn/exchange/story20090330-107855\#sthash.76AcY54n.d puf (accessed 07.10.15).

Taylor, Jay (1976), China and Southeast Asia: Peking's Relations with Revolutionary Movements, London: Praeger.

Thompson, Peter A. (2009), "Market Manipulation? Applying the Propaganda Model to Financial Media Reporting", Westminster Papers in Communication and Culture, 6(2): 73-96.

Wu, Fei (2013), "Zhong Mei E xiwang chongsu APEC-ge yousuo tu" (China, the USA, Russia hope to reshape APEC-each has a plan), Lianhe zaobao, October 12, available at: http://www.zaobao.com.sg/special/report/politic /sinous/story20131012-263765/page/0/1\#sthash.ZLe4jKaX.dpuf (accessed 06.10.15).

Yang, Sheng. (2017), "Lee Family Feud Rocks Singapore", Global Times, available at: http://www.globaltimes.cn/content/1051967.shtml (accessed: 05.09.2017).

You, Runtian (2010), "Wu zizheng: Zhongguo jingji shinian hou keneng chaoyue Meiguo" (Advisor to Wu: China's economy could pass the USA's after a decade), Lianhe zaobao, February 17, available at: http://ww w.zaobao.com.sg/special/sg-cn/business/story20100217-108143\#sthas h.AMUNbPmN.dpuf (accessed 08.10.15).

- - (2013), "Shangmugen: Yaxi'an shiguo dou zhichi tisheng Yaxi'an-Zhongguo zi mao xieding" (Shanmugam: all 10 ASEAN countries support the ASEAN-China FTA), Lianhe zaobao, August 30, available at: http://www.zaobao.com.sg/special/sg-cn/bilateral/story20130830-24668 9\#sthash.JOM5KGfp.dpuf (accessed 06.10.15).

Yumul, Arus and Umut Özkirimli (2000), "Reproducing the Nation: 'Banal Nationalism' in the Turkish Press", Media Culture Society 22(6): 787-804.

Zhang, Furun (2010), "Zhong Xin weida youyi de xiangzheng" (Symbol of great friendship between China and Singapore), Lianhe zaobao, November 16, available at: http://www.zaobao.com.sg/forum/letter/singapore/story201 01116-43908\#sthash.ZhTCuxXE.dpuf (accessed 07.10.15).

- - (2011), "Chunjie lailin hua shicheng" (Spring Festival is approaching for Lion City), Lianhe zaobao, January 29, available at: http://www.zaoba o.com.sg/forum/letter/singapore/story20110129-43888\#sthash.yuNhsu9 b.dpuf (accessed 07.10.15).

Zhang, Juyan and Glen T. Cameron (2003), “China's Agenda Building and Image Polishing in the US: Assessing an International Public Relations Campaign", Public Relations Review, 29: 13-28.

Zhao, Hong (2010), "Zhongguo-Yaxi'an nengyuan anquan yu Nan Zhongguo Hai de chongtu yu hezuo" (China-ASEAN conflict and cooperation on energy security and the South China Sea), Lianhe zaobao, August 20, available at: 
http://www.zaobao.com.sg/special/report/politic/cnpol/story20100820-1 38528\#sthash.VIs7BUsb.dpuf (accessed 08.10.15).

Zhao, Kaijian (2013), "Xinren jituan zongcai: Jiadezhi de jie xialai zhuanzhu xin zhong shichang" (New Group President: CapitaLand to focus on new Chinese markets), Lianhe zaobao, January 4, available at: http://ww w.zaobao.com.sg/consumer/property/private/story20130104-27451\#stha sh.gHVMrf2Y.dpuf (accessed 07.10.15).

Zhao, Wanyi (2015), "Xuezhe: Nan Zhongguo Hai zhengyi yingxiang Zhongguo he Yaxi'an guanxi" (Scholars: the South China Sea dispute influences Sino-ASEAN relations)", Lianhe zaobao, August 9, available at: http://ww w.zaobao.com.sg/special/report/politic/southchinasea/story20150809-51 2498\#sthash.wGgqg82B.dpuf (accessed 07.10.15).

Zheng, Yongnian (2010), "Zhongguo waijiao: xin siwei cai hui you xin geju" (China's diplomacy: new patterns of thinking), Lianhe zaobao, November 16, available at: http://www.zaobao.com.sg/special/report/politic/cnpol/story 20101116138230\#sthash.IlaNbeBh.dpuf (accessed 06.10.15).

- - (2011), "Zheng Yongnian: Zhongguo yu Yazhou anquan zhixude weilai" (Zheng Yongnian: China and the future of the Asian security order), Lianhe zaobao, July 26, available at: http://www.zaobao.com.sg/special/report/po litic/cnpol/story20110726-139965\#sthash.cOnndrZD.dpuf (accessed 06. 10.15).

Zhou, Viola (2016), "Blow-by-Blow Account of the China-Singapore Spat over Global Times' South China Sea Report", South China Morning Post, available at: http://www.scmp.com/print/news/china/diplomacy-defence/article/2

023364/blow-blow-account-china-singapore-spat-over-global (accessed: 05.09.2017).

Daniel R. Hammond is Lecturer in Chinese Politics and Society at the University of Edinburgh. 